\title{
Optimization of Lighting Conditions With LED Light Sources
}

${ }^{* 1}$ Olga E. Zheleznikova, ${ }^{2}$ Ivan V. Blentsov, ${ }^{3}$ Olga S. Voynova, ${ }^{4}$ Dmitry S. Batarshev

1,2,3,4 Federal State Budgetary Educational Institution of Higher Education "National Research Ogarev Mordovia State University"

Email: sarstf@mail.ru,blentsov@mail.ru,olchik.voinova@yandex.ru,batarshev.dmitry@yandex.ru

Received: 07th February 2020, Accepted: 02nd March 2020, Published: 30th April 2020

\begin{abstract}
The article is devoted to the description of the results of experimental studies evaluating the effectiveness of lighting installations with LEDs. It was found that LED lighting does not cause harmful effects on the visual organ and the human body as a whole. Changes in the functional parameters of the visual organ that occur during visual work are included in the corresponding boundaries of physiological vibrations and are reversible. We estimated the integral indicators of LED lighting efficiency and showed practical significance of the results.
\end{abstract}

Keywords

LED Lighting, Comprehensive Technique, Experimental Research Installation, Visual Functions, Visual Fatigue, Visual Performance, Lighting Efficiency.

\section{Introduction}

Given the role of lighting in the development of modern civilization, it is important that it is created by means that are safe for human vision and health, when taking into account the requirements of energy conservation. At present, the most promising are lighting devices based on light emitting diodes (LEDs), whose light output is 150$160 \mathrm{~lm} / \mathrm{W}$, which already exceeded $300 \mathrm{~lm} / \mathrm{W}$ with a service life of 50 thousand hours and above for laboratory samples. Moreover, the harmful cataractogenic effect of short-wave radiation on the lens is currently known. A number of studies show that first-generation LED light sources (LED LS) can negatively affect the retina [1 - 7]. The danger is caused by short-wave blue and violet radiation, which has an increased intensity in the spectrum of these sources. This radiation can affect the retina in a variety of ways, including photochemical radiation - shortwavelength photons can cause chemical changes in the retina structures. Despite the insufficient knowledge of the effects of LED lighting on the health of people of different age groups and the assessment of the long-term risks of such an impact, a widespread introduction of modern LED LS is carried out in all areas of human activity, including schools and universities, in our country. In this regard, comprehensive research is needed in this area.

\section{Main Part}

The purpose of this work is to increase the efficiency of lighting conditions for LED LS with regard to their photobiological safety.

We used the developed experimental research installation (ERI) for general lighting, described in detail in [8]. A lighting installation (LI) with fluorescent lamps (FL) was selected as the base when comparing lighting options. We selected the LED lamps of type Cap Flat 66-16 of the Russian-Korean Joint Venture NEPES RUS and of type DVO12-38-001 Prizma of OJSC Ardatovskiy Lighting Engineering Plant, as well as the LL fixtures of type LVO04-4×14-041 PRS for the ERI. The values of the correlated color temperature (CCT) of lam radiation are 3000, 4000 and $5000 \mathrm{~K}$. The Common Use Center "Lighting Metrology" of the FSBEI HE "Moscow State University named after N.P. Ogarev" measured photometric and spectrocolorimetric parameters of the selected fixtures. Figures 1 and 2 show the spectra of their radiation. 


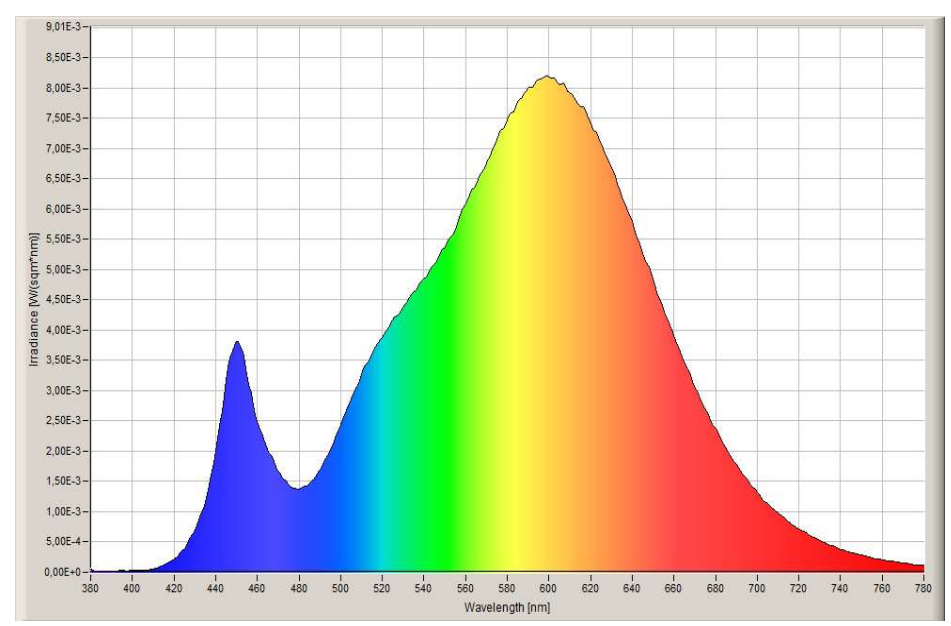

a)

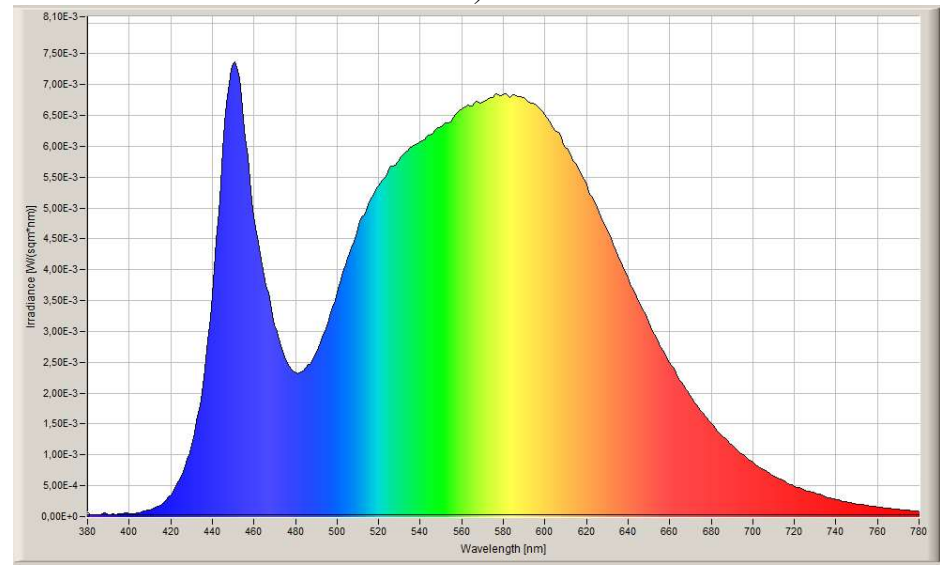

b)

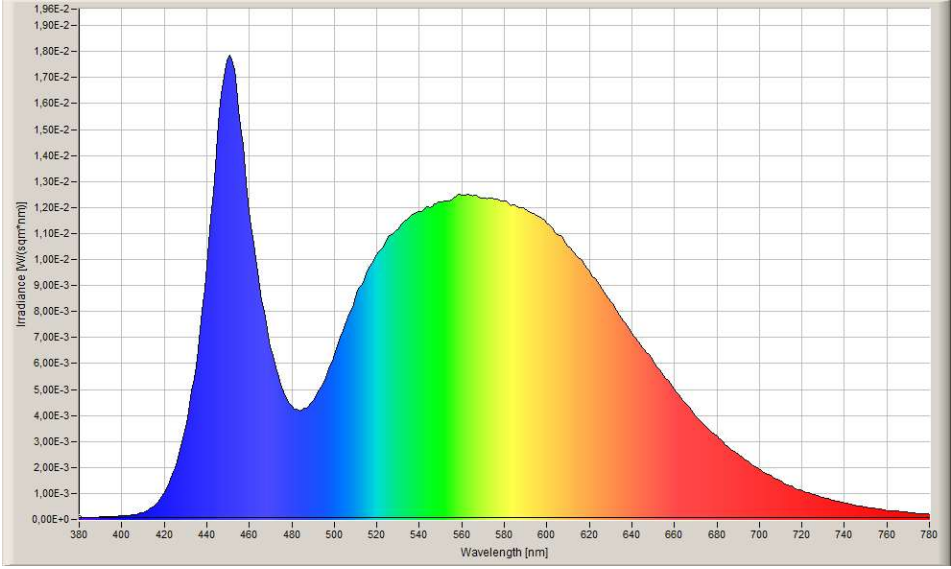

c)

Fig. 1: The Emission Spectra of LED Lamps

a) Cap Flat 66-16 (LLC NEPES RUS), CCT = 3000 K, b) Cap Flat 66-16 (LLC NEPES RUS), CCT = 4000 K, (LED Manufactured by LLC NEPES RUS), c) DVO 12-38-416 (OJSC ASTZ), CCT = 5000 K,

(LED Manufacture by Seoul Semiconductor) 


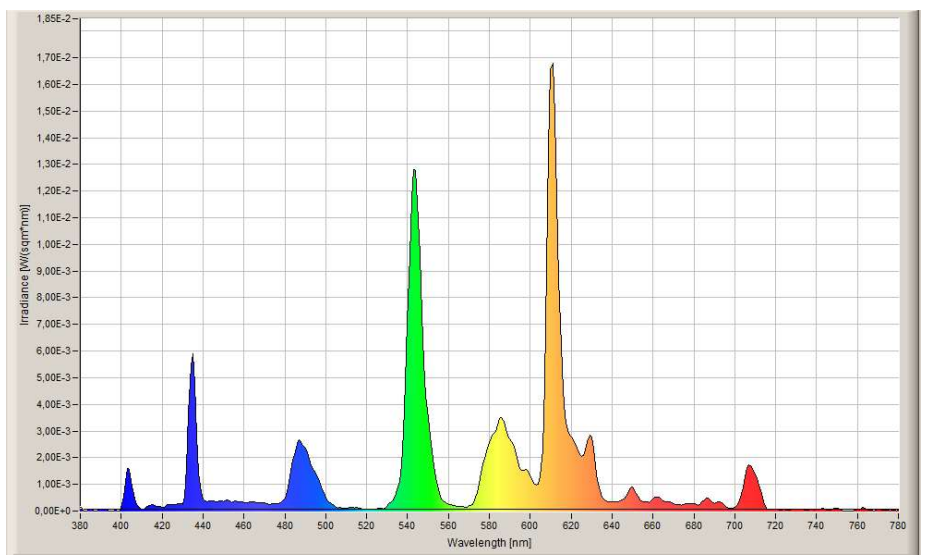

a)

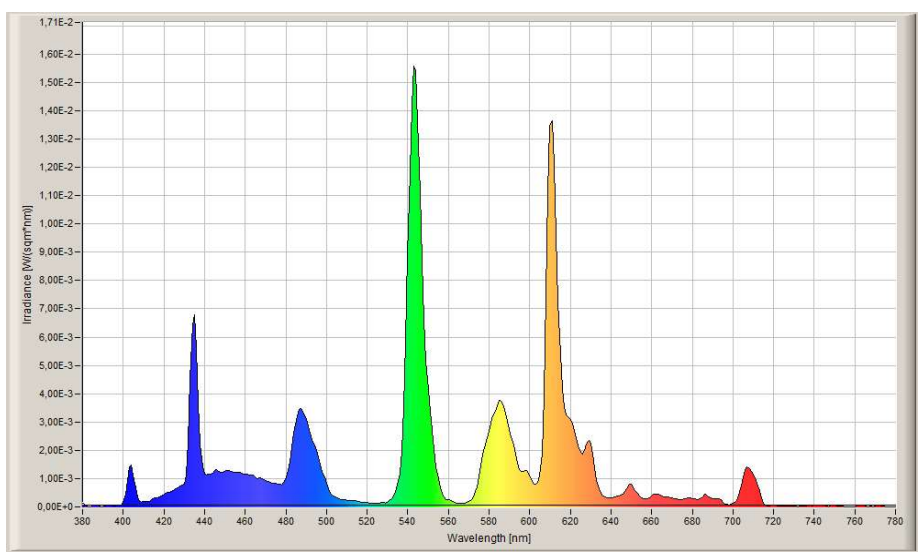

b)

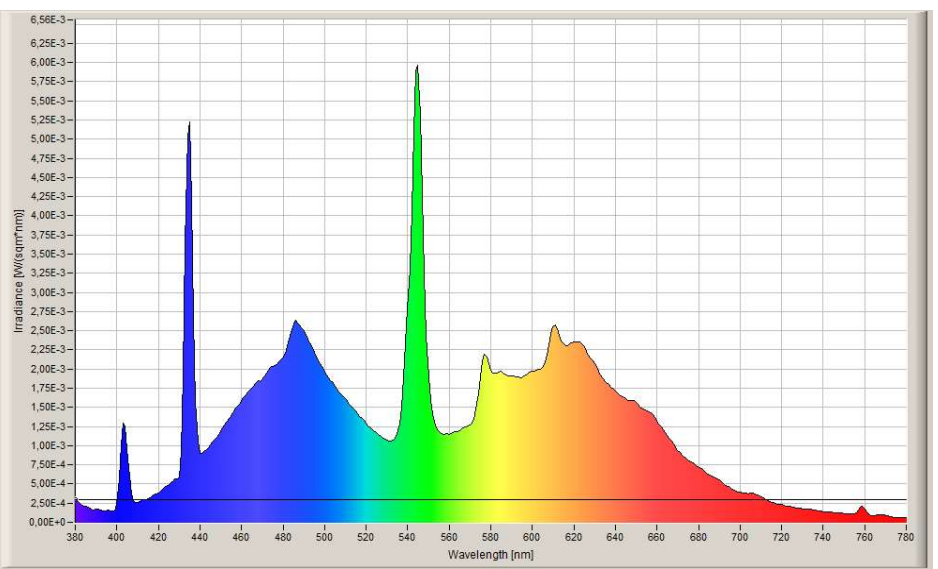

c)

Fig. 2: The Emission Spectra of FL Lamps a) LVO 04-4x14-041 PRS with FL T5 FH 14W HE (Osram), CCT = 3000 K, b) LVO 04-4x14-041 PRS with FL Master TL5 HE 14W (Philips), CCT = 4000 K, c) LVO 04-4x18-041 PRS with FL T8 Osram L $18 \mathrm{~W}, \mathrm{CCT}=5000 \mathrm{~K}$ 
The lighting options were previously modeled by us in the DIALux program in order to fulfill the requirements of [9]. Changing the illumination $\mathrm{E}$ of the working surface was achieved using adjustable ballasts and drivers (according to the DALI protocol). Studies were conducted at three E levels: 200, 400 and 1000 lux.

Based on the analysis of theoretical and experimental materials, we have developed a comprehensive methodology for assessing the influence of LED lighting conditions on the psychophysiological parameters of the human body [10].

Before the start of our research, a group of volunteer students aged 20-25 years old was examined at the Republican Ophthalmological and Psychiatric Hospitals of Saransk.

The examination at the Republican Ophthalmological Hospital included: determination of refraction; determination of visual acuity; computer tomogram of the retina. The refraction was predominantly emmetropic visual acuity was 1.0 in both eyes, color perception was without pathology in all the selected subjects.

The examination at the Republican Psychiatric Hospital included: studies of mental functions; a number of functional indicators of the brain; studies of the immune status and hormonal profile.

The selected subjects in the amount of 60 people were randomly divided into two groups of 30 people each: control (experiment with FL lighting) and main (experiment with LED lighting). The number of subject and the number of experiments were determined based on the requirements for obtaining statistically reliable data and regulating the research time. We drew up an experimental plan and work schedules for each group, taking into account human daily biorhythms. The functional load was one and a half hours of visually intense work of the proofreader type with the mental component. The combined UGR indicator was in the range of 10-14, the percent flicker was $0.2-0.6 \%$ in all the lighting options that we studied.

Before the start of experimental studies, all the subjects underwent training for 10 days according to research methods to obtain stable results. During the experiment, under the given lighting conditions, we measured the volume of absolute accommodation, time of achromatic adisparopia, CFFF (critical frequency of flicker fusion (at KPFK-99 Psychomat), and blood pressure. At the end of work, the subjects filled out questionnaires for a subjective assessment of lighting conditions. Before starting the visually intense work and after its completion, we measured (monocularly) the color chromatic threshold using an anomaloscope AN-59 and a blind spot projection of the visual organ (using the campimetry method).

\section{Results and Discussion}

Examination of the visual organ. Studies of the absolute accommodation volume (AAV) showed that when intense visual work is performed in all considered lighting options, its values decrease (Tables 1 and 2).

Table 1: The Change in the Absolute Accommodation Volume after Visual Load with various LED

\begin{tabular}{|c|c|c|c|c|c|c|c|}
\hline \multirow[b]{3}{*}{$\mathrm{E}, 1 \mathrm{x}$} & \multirow[b]{3}{*}{$\begin{array}{l}\mathrm{CCT}, \\
\mathrm{K}\end{array}$} & \multicolumn{4}{|c|}{ Lighting Options } & \multirow{2}{*}{\multicolumn{2}{|c|}{ Correlation ratio }} \\
\hline & & \multicolumn{2}{|c|}{ Before work } & \multicolumn{2}{|c|}{ After work } & & \\
\hline & & $\begin{array}{l}\text { OAA, dptr., } \\
\bar{x}\end{array}$ & $\begin{array}{l}\text { Confidence } \\
\text { interval, } \\
t \cdot \sigma_{\bar{x}}\end{array}$ & $\begin{array}{l}\text { OAA, } \\
\text { dptr., } \\
\bar{x}\end{array}$ & $\begin{array}{l}\text { Confidenc } \\
\text { e interval, } \\
t \cdot \sigma_{\bar{x}}\end{array}$ & $\begin{array}{l}\mathrm{r} \quad \text { (between } \\
\text { before and } \\
\text { after work) }\end{array}$ & $\mathrm{p}(\mathrm{r})$ \\
\hline 200 & & 8.70 & 0.10 & 8.40 & 0.21 & 0.75 & $\mathrm{p}<0.05$ \\
\hline 400 & 3000 & 9.00 & 0.21 & 8.80 & 0.12 & 0.85 & $p<0.01$ \\
\hline 1000 & & 9.90 & 0.16 & 9.70 & 0.19 & 0.73 & $\mathrm{p}<0.05$ \\
\hline 200 & & 9.40 & 0.13 & 9.00 & 0.16 & 0.66 & $\mathrm{p}<0.05$ \\
\hline 400 & 4000 & 9.70 & 0.17 & 9.50 & 0.19 & 0.65 & $\mathrm{p}<0.05$ \\
\hline 1000 & & 10.10 & 0.13 & 10.20 & 0.18 & 0.14 & - \\
\hline 200 & & 9.30 & 0.11 & 8.70 & 0.15 & 0.79 & $\mathrm{p}<0.05$ \\
\hline 400 & 5000 & 9.70 & 0.13 & 9.40 & 0.18 & 0.66 & $\mathrm{p}<0.05$ \\
\hline 1000 & & 10.00 & 0.22 & 9.80 & 0.24 & 0.63 & $\mathrm{p}<0.05$ \\
\hline
\end{tabular}


Table 2: The Change in the Absolute Accommodation Volume after Visual Load with various FL Lighting Options

\begin{tabular}{|c|c|c|c|c|c|c|c|}
\hline \multirow{2}{*}{$\mathrm{E}, 1 \mathrm{x}$} & \multirow{2}{*}{$\begin{array}{l}\mathrm{CCT}, \\
\mathrm{K}\end{array}$} & \multicolumn{2}{|c|}{ Before work } & \multicolumn{2}{|c|}{ After work } & \multicolumn{2}{|c|}{ Correlation ratio } \\
\hline & & $\begin{array}{l}\text { OAA, dptr., } \\
\bar{x}\end{array}$ & $\begin{array}{l}\text { Confidenc } \\
\text { e interval, } \\
t \cdot \sigma_{\bar{x}}\end{array}$ & $\begin{array}{l}\text { OAA, dptr., } \\
\bar{x}\end{array}$ & $\begin{array}{l}\text { Confidence } \\
\text { interval, } \\
t \cdot \sigma_{\bar{x}}\end{array}$ & $\begin{array}{l}\mathrm{r} \text { (between } \\
\text { before and } \\
\text { after work) }\end{array}$ & $\mathrm{p}(\mathrm{r})$ \\
\hline 200 & \multirow{3}{*}{3000} & 8.60 & 0.21 & 8.20 & 0.12 & 0.73 & $\mathrm{p}<0.01$ \\
\hline 400 & & 8.80 & 0.20 & 8.60 & 0.10 & 0.69 & $\mathrm{p}<0.05$ \\
\hline 1000 & & 9.60 & 0.14 & 9.40 & 0.10 & 0.74 & $\mathrm{p}<0.01$ \\
\hline 200 & \multirow{3}{*}{4000} & 8.80 & 0.14 & 8.30 & 0.16 & 0.69 & $\mathrm{p}<0.05$ \\
\hline 400 & & 9.10 & 0.15 & 8.80 & 0.10 & 0.77 & $\mathrm{p}<0.01$ \\
\hline 1000 & & 9.80 & 0.14 & 9.60 & 0.12 & 0.85 & $\mathrm{p}<0.001$ \\
\hline 200 & \multirow{3}{*}{5000} & 8.70 & 0.29 & 8.20 & 0.27 & 0.63 & $\mathrm{p}<0.05$ \\
\hline 400 & & 9.10 & 0.17 & 8.70 & 0.23 & 0.83 & $\mathrm{p}<0.001$ \\
\hline 1000 & & 9.70 & 0.10 & 9.40 & 0.07 & 0.72 & $\mathrm{p}<0.05$ \\
\hline
\end{tabular}

The determination of the reliability of AAV changes as a result of visual load according to Student's $t$-test with $p$ $<0.05$ made it possible to state that significant shifts were found in the AAV values in almost all lighting options. At the same time, they did not exceed the limits of natural variations of this indicator of the accommodative function of visual organ ( 0.5 - 1.5 diopters).

An assessment of the influence of the spectral composition on the change in the considered accommodation indicator at a constant E level according to Student's $t$-test was revealed in the compared options at CCT $4000 \mathrm{~K}$ at all E levels and at CCT $5000 \mathrm{~K}$ at E levels of 200 and 400 lux. The highest AAV values are recorded with LED lighting. The excess of AAV after work with LED lighting compared with the basic lighting option at CCT 4000 $\mathrm{K}$ in the E range of $200-1000$ lux was $0.6-0.7$ diopters $(6.3-8.4 \%)$, at CCT $5000 \mathrm{~K}$ in the E range of $200-400$ lux $-0.5-0.7$ diopters $(6.0-8.0 \%)$. That is, it was found that the visual organ better accommodates at LED lighting (with CCT 4000 and $5000 \mathrm{~K}$ ). This is due to the greater activity of the ciliary muscle and is apparently associated with the LED radiation spectrum.

The influence of the spectral composition of radiation at a constant E level on the change in the time of achromatic adisparopia during operation in the compared options is characterized by a high degree of significance. The time of achromatic adisparopia both before and after work turned out to be longer during LED lighting. This indicates its beneficial effect on the muscular system of the visual analyzer.

Thus, it was revealed that LED lighting creates the best conditions for the accommodative-muscular apparatus of the visual organ.

When assessing the state of retina by computed tomography, we found that the subjects of control and main groups retained the foveola profile and had broken architectonics of the retina after experiment. Statistical processing of the survey results in both groups did not reveal statistically significant differences between the studied parameters ( $p>0.05$ according to Student's $t$-test). That is, the state of retina remains without significant changes.

The study of the projection area of the blind spot showed that retinal fatigue, assessed according to the state of peripheral vision, leads to a significant increase in the physiological area of the blind spot after intense visual work. The increase range in the projection of the optic nerve in relation to the initial for the FL lighting options was $6.57 \div 12.06 \%$; for the LED lighting options $-3.87 \div 10.77 \%$. Comparison of the dynamics of the studied indicator revealed that LED lighting contributes to less visual fatigue (VF) compared with FL lighting at CCT $3000 \mathrm{~K}(p<0.05)$.

In the course of experiment, the uneven nature of change in the thresholds of color differentiation was established under various lighting options. According to the obtained results, the functional state of retina was not the same during visual work under the LED and FL lighting conditions, which is obviously associated with photochemical reactions in the retina, which can be inhibited and amplified by radiation in different parts of visible spectrum. There was an influence of the spectral composition of radiation only on the c-receptor of retina for radiation with CCT $4000 \mathrm{~K}$ at E 1,000 lux and CCT $5000 \mathrm{~K}$ at E 400 and 1,000 lux $(p<0.05)$. For other options, the influence of the spectral composition was insignificant. This can be explained by the nature of visual tasks - working with achromatic objects, as well as favorable spectral composition of radiation.

Studies of the state of the central link of visual organ before and after work according to the CFFF method did not reveal the most preferred composition of radiation: Student's $t$-test did not confirm the significance of differences in the entire studied range of E and CCT. Therefore, we can conclude that the CFFF indicators for LED and FL lighting do not differ significantly. 
The research results led to the conclusion that the reduction in CFFF during the experiment is associated with the visually-intense work performed; this process is reversible - the indicators were restored to their original values by the beginning of the next day. That is, the LED lighting did not exert the inhibitory effect on the state of the central nervous system.

Determination of integral indicators of the LED lighting effectiveness by the degree of memory and visual performance. Analysis of the visual performance study results by the correction method showed the benefits of LED lighting from the standpoint of ensuring greater visual performance. The highest value of the visual performance ratio $I$ at LED lighting was established at CCT $4000 \mathrm{~K}$. Thus, compared with FL at E 200 lux, it is higher by $11.8 \%$; at E 400 lux - by $14.9 \%$; at E 1,000 lux - by $12.4 \%$.

The paired correlation coefficient $r$ confirmed $(p<0.05)$ the presence of a positive relationship between AAV and $I$ after visual work. This allowed suggesting that a certain contribution to an increase in the visual working capacity ratio at LED lighting was made by better work of the accommodative-muscular apparatus.

The study results of the quality of work showed that its indicator decreased during visual load. However, the reliability of reducing the accuracy ratio according to Student's $t$-test was found only in the LED lighting conditions at CCT $4000 \mathrm{~K}$ (E 400 and 1,000 lux); at CCT $5000 \mathrm{~K}$ (E 400 lux). Differences in the quality of work were insignificant when comparing the LED and FL lighting options.

The results of VF calculation for the dynamics of the time threshold of achromatic adisparopia are presented in Figure 3. It was found that a smaller VF was developed with LED lighting in the course of an hour and a half of visually intense work. The smallest VF was noted for CCT 4000 and $5000 \mathrm{~K}$ at E 400 lux with LED lighting. The reliability of influence of the lighting spectral composition on VF is proved in all studied lighting options with $p$ $<0.05$ according to Student's $t$-test.

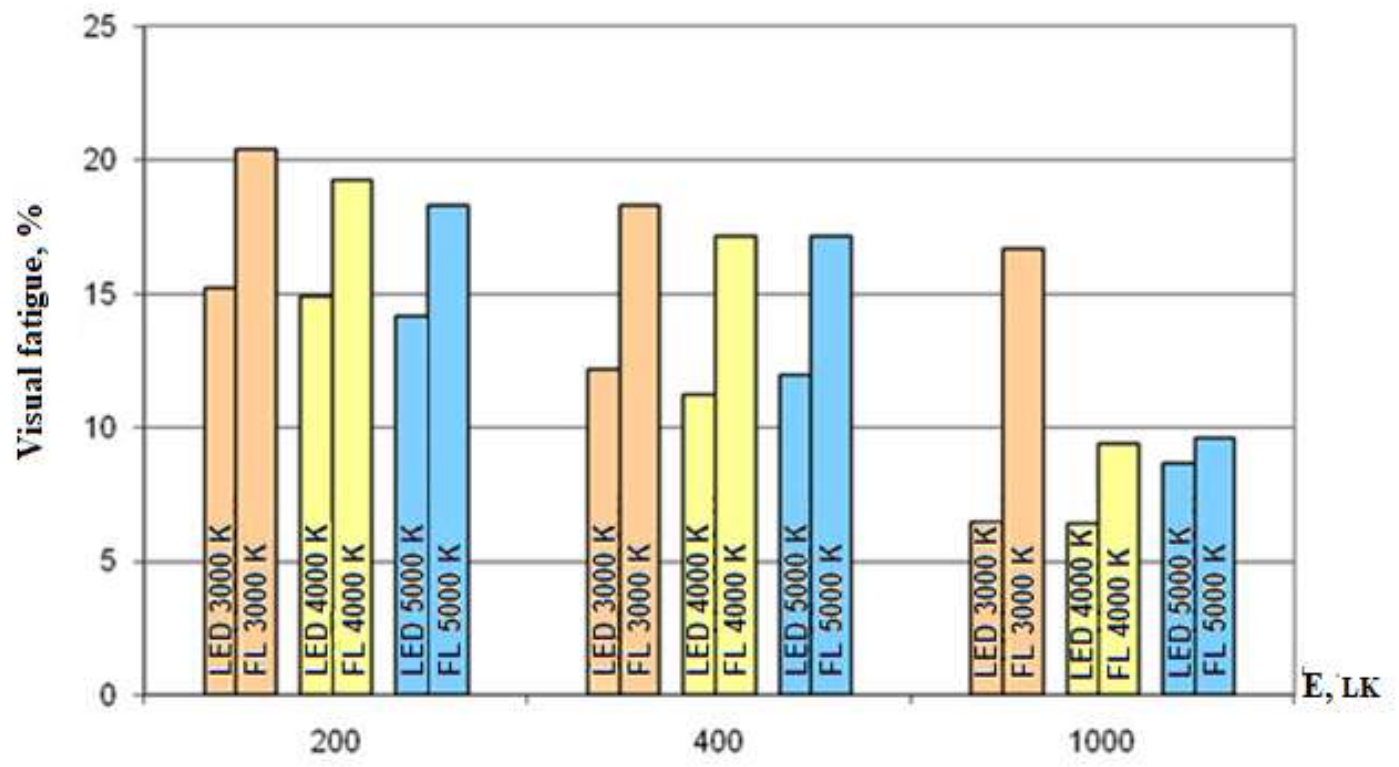

Fig. 3: Visual Fatigue (by the Achromatic Adisparopia Method)

The analysis of integral indicators of lighting efficiency allowed making the following conclusion: the LEDcreated light medium contributed to providing higher visual performance and less VF. LED lighting can be considered as favorable from a hygienic position when performing visually intense work.

\section{Conclusion}

A series of experimental studies devoted to the influence of lighting conditions on the functional indicators of the organ of vision and the human body as a whole showed that the developed comprehensive methodology for the psychophysiological and hygienic assessment of LED lighting effectiveness has been successfully tested in laboratory conditions.

The analysis of experimental study results reliably showed that LED lighting of does not have a negative effect on the organ of vision and the human body as a whole (age group: 20 - 25 years). The changes of the studied functional parameters of the organ of vision and organism occurring during visual work are included in the corresponding boundaries of physiological fluctuations and are reversible.

The studies performed under various lighting conditions (LED and LL) revealed a close relationship between the functions of vision and the compensatory-adaptive response of the body and the stability of adaptive systems 
responsible for sensitivity regulation of the organ of vision and the body as a whole. The results of the studies can be used to develop practical recommendations for light environment optimization with LED, taking into account their photobiological safety.

\section{References}

1. Lighting environment for human: science, industry and law, 2016. Lighting engineering, 1: $45-49$.

2. "Blue danger level" declared in the plentiful light, 2017. Semiconductor lighting engineering, 4: 62 - 65.

3. Wright, M, 2010. Debate continues over the impact of light on human health LEDs magazine, 46: 25.

4. Behar-Cohen, F., Martinsons, C., Vienot, F., Zissis G., Barlier-Sals, A., Cesarini, J.P., Enouf O., Garcia, M., Icaud, S., Attia, D., 2011. Light-emitting diodes (LED) for domestic lighting: Any risks for the eye? Progress in Retinal and Eye Research, 30: 239 - 257.

5. Kitchel, E., 2000. The Effects of Blue Light on Ocular Health. J. Vis. Impair. Blind, 94 (6): 357 - 361.

6. Margrain, T.H., 2004. Do blue light filters confer protection against age-related macular degeneration? Progress in retinal and Eye Research, 23: 523 - 553.

7. Kuchma, V.R., Teksheva, L.M., Sukhareva, L.M. et al., 2013. Hygienic basis for the use of LEDs in the artificial lighting systems. M.: FSBI "Scientific Center for Children's Health" of the RAMS, p. 246.

8. Zheleznikova, O. E., Mikaeva, S. A., Ageev, S. N., Blenstov, I. V., Voynova, O. S., 2018. The assessment of light environment with the first generation leds Indonesian Journal of Electrical Engineering and Informatics, 6(3): $235-243$.

9. GOST R 54350-2015. Lighting devices. Lighting requirements and test methods.

10. Zheleznikova, O. E., Amelkina, S.A., Sinitsyna, L.V., Kiryukhina, S.V., 2013. Development of a comprehensive methodology for assessing the influence of LED lighting conditions on the state of visual organ and the human body as a whole. Natural and technical sciences, 5 (67): $249-257$. 